Article

\title{
Residents' Environmental Conservation Behaviors at Tourist Sites: Broadening the Norm Activation Framework by Adopting Environment Attachment
}

\author{
Yuling Zhang ${ }^{1}$, Jie Zhang ${ }^{2, *}$, Yuyao Ye ${ }^{1}$, Qitao Wu ${ }^{1}$, Lixia Jin ${ }^{1}$ and Hongou Zhang ${ }^{1, *}$ \\ 1 Guangzhou Institute of Geography, Guangzhou 510070, China; zhylde@gdas.ac.cn (Y.Z.); \\ yeyuyao@gdas.ac.cn (Y.Y.); wuqitao@gdas.ac.cn (Q.W.); jlx906@gdas.ac.cn (L.J.) \\ 2 School of Geographic and Oceanographic Science, Nanjing University, Nanjing 210046, China \\ * Correspondence: jiezhang@nju.edu.cn (J.Z.); hozhang@gdas.ac.cn (H.Z.); Tel.: +86-025-8359-7097 (J.Z.); \\ +86-020-3765-6557 (H.Z.)
}

Academic Editor: Vincenzo Torretta

Received: 16 April 2016; Accepted: 13 June 2016; Published: 17 June 2016

\begin{abstract}
Understanding the factors that affect residents' environmental conservation behaviors help in managing the environment of tourist sites. This research provides an integrative understanding of how residents near tourist sites form their environmental conservation behaviors by merging the norm-activation model and cognitive-affective model into one theoretical framework. Results of the structural analysis from a sample of 642 residents showed that this study's proposed composite model includes a satisfactory level of predictive power for environmental conservation behaviors. The findings identify the following two dimensions of awareness of environmental consequences as having a key role in predicting environmental conservation behaviors: (1) awareness of positive consequences of environmental protection; and (2) awareness of disaster consequences. Results also show that environment attachment and personal norms about environmentalism played a mediating role between awareness of environmental consequences and environmental conservation behaviors, and that personal norms about environmentalism were the most powerful factor in predicting behaviors. Several practical implications were derived from the research findings that can contribute to environment management policy both within and outside the field of tourism, mostly notably: (1) how the effective promotion of these factors can encourage environmental conservation behaviors for residents; and (2) how governments can develop and implement environmental management measures to improve locals' awareness of positive consequences of environmental protection.
\end{abstract}

Keywords: environmental conservation behaviors; awareness of environmental consequences; environment attachment; personal norms

PACS: J0101

\section{Introduction}

\subsection{Background}

For tourism, an environment change (e.g., global warming, extreme weather, and climate events) is not considered to be a remote event, but rather a phenomenon that already affects the sector and certain destinations; in particular, mountain regions [1] and coastal destinations, among others [2,3]. Environment is an essential resource for tourism, especially in tourist sites that focus on natural features. Changing climate and weather patterns at tourist destinations and within tourist generating countries overall can significantly affect tourists' comfort levels and travel decisions [4]. Thus, tourist demand patterns and flows might change. The decision of tour operators and potential tourists 
to visit a particular place is shaped by perceptions regarding personal safety, suitability of access, availability of accommodations, and likelihood of travel disruption [5]. Therefore, in the event of extreme weather, visitors may adapt and choose to travel to safer places, leaving the original destination with subsequent (and negative) economic impacts. Tourism is particularly sensitive to environmental quality. The degradation of environmental quality of a destination (e.g., air and water pollution, environmental noise, vegetation loss and wildlife displacement) will reduce its attractiveness and competitiveness compared with other destinations, and will negatively affect its further development of tourism [6]. Meanwhile, the environmental impacts of tourism should not be ignored, especially in popular destinations, because of suffering more environmental interference by tourism activities. Tourism generates many negative environmental consequences, such as solid waste generation, water and air pollution, and habitat disturbance, all of which can seriously threaten the very environment upon which tourism depends [7]. The positive effects of tourism, on the other hand-such as providing local employment opportunities and increasing residents' income and the local tax base-can promote environment and resource protection if appropriate measures are taken. The question, then, is how to manage the environment from the perspective of encouraging people, especially local residents, to protect the environment at tourist sites. This study employs research on factors affecting residents' environmental conservation behaviors and the creation of a theoretical model to explain environmental conservation behaviors as the methods to answer this question.

There has been a growing trend, commencing in the late 1960s and erupting into full force in the 1980s, toward incorporating public participation in environmental conservation. Key theorists, such as Schwartz [8], Ajzen [9,10], and Stern [11], have pushed the factors of norms, values, beliefs, attitude, behavioral intentions, and perceived behavioral control to the forefront of environmental conservation behavior prediction. Other factors, such as place attachment [12-14], emotion [15], experience [16-19], settings [20], community involvement [21], and socio-demographic factors (e.g., age, gender, socioeconomic status, education, ethnicity, and religion) [22], are also powerful predictors of environmental conservation behavior. Researchers have increasingly sought to link social-psychological factors to environmental conservation behaviors through theoretical conceptualization and empirical case studies, such as the theory of planned behavior $[9,23,24]$, the norm-activation model [25,26], the value-belief-norm theory [6,11,27], rational-choice models $[9,28]$, the theory of place attachment [12,29], and the exploration and validation of a comprehensive model $[6,27]$.

In addition, researchers in a variety of fields and contexts have repeatedly evaluated the appropriateness of using either a norm-activation model or value-belief-norm theory involving pro-social motives as well as the adequacy of employing rational-choice models (e.g., the theory of planned behavior) involving self-interested motives in the context of environmental conservation behaviors [27]. Others have noted that awareness of environmental consequences includes both pro-social and self-interested motives, and that using a norm-activation model that incorporates both motivations might lead to better predictions of environmental conservation behaviors. Moreover, although many theorists and practitioners have acknowledged that there is a set of affective bonds or associations between individuals, groups, communities, and their daily life environment [30], and that these associations ultimately influence behaviors, few have examined the practical linkage between environment attachment and environmental conservation behaviors. All tourism stakeholders have an affinity toward tourist sites, with local residents holding the strongest bond, as their livelihood and well-being are closely related to the resources within and environment of tourism sites. Meanwhile, the trend toward prioritizing local participation in environmental conservation initiatives stems, in part, from the beliefs that local involvement could reduce resistance or hostility toward conservation efforts and that restricting local environment access without offering an alternative is morally irresponsible. This study considers only host residents' environmental conservation behaviors, and the research questions that framed this investigation are as follows: 
(a) Does awareness of environmental consequences affect residents' environmental conservation behaviors at tourist sites?

(b) Is there a linkage between residents' environment attachment and environmental conservation behaviors?

(c) Which factor is most powerful to predict residents' environmental conservation behaviors at tourist sites?

To answer these questions, we adopted a hypothetical model that was empirically applied to questionnaire data through structural equation modeling (SEM).

\subsection{Theory and Research Hypotheses}

Schwartz's norm-activation model has been used widely in environmental, psychological, and behavioral studies to analyze the impact of moral norms on behaviors [25,31] and to predict environmental conservation behaviors $[27,32,33]$. Schwartz points out that the relationship between moral norms and behavior is dependent on how individuals define an action situation [31]. Specifically, he identifies two conditions that must exist before individuals define situations such that their moral norms will be "activated" and, consequently, affect their behavior. First, actors must have some awareness that their actions may have consequences on the welfare of others, or action consequence (AC); second, actors must admit some responsibility for these actions and their consequences, or action responsibility (AR) [31]. The causal chain of the norm-activation model is AC $\rightarrow$ AR $\rightarrow$ personal norm $\rightarrow$ behavior. Awareness of environmental consequences has broader applications in the field of environmentalism than AC, because both natural and human-made events have positive or negative consequences on the welfare of affected people [11]. This study's general presumption is that people who sense that an environmental condition has direct or indirect consequences (AC) for things that they value will be predisposed to take action. In this study, AC is, specifically, awareness of environmental consequences at tourist sites. Although Schwartz emphasized the mediating effects of AR between $\mathrm{AC}$ and personal norms, several empirical researches have verified that $\mathrm{AC}$ affects personal norms directly [34-36]. Meanwhile, Harland and colleagues have argued that AR and personal norms have similar enough meaning as measurement indicators that they can be thought of as one conceptual category [37]. Adopting this thinking, this study directly explore the relationship between awareness of environmental consequences $(\mathrm{AC}$, including three dimensions: awareness of negative environmental consequences, awareness of the positive consequences of environmental protection, and awareness of disaster consequences, after factor analysis), personal norms, and environmental conservation behaviors (including the two dimensions: daily environmental conservation behaviors and concern for environmental protection at tourist sites). It ignores the mediating effects of AR. Thus, we propose five hypotheses: $1 \mathrm{a}, 1 \mathrm{~b}, 1 \mathrm{c}, 2 \mathrm{a}$, and $2 \mathrm{~b}$ (Table 1 ).

The most important aspect of decision-making and behavioral processes is understanding one's cognitive and emotional views [38]. With regard to the relationship between cognition and emotion, empirical verification of the cognitive-affective model is widely accepted [39]. Emotions occur as a result of the cognitive appraisal of a person-environment situation [40-42]. Several previous studies have established that emotions are influenced by disconfirmation [43], perceived quality [44], perceived value [45], and beliefs and evaluations [46]. Zhang et al. indicated that individuals may experience positive emotions about environmental conservation for a tourist site, induced by cognition of landscape experience [15]. Awareness of environmental consequences is a type of cognition, and environment attachment can be classified as an emotion; thus, hypotheses $3 a, 3 b$, and $3 c$ were proposed (Table 1). 
Table 1. Hypotheses.

\begin{tabular}{cl}
\hline Number & Hypothesis \\
\hline $1 \mathrm{a}$ & $\begin{array}{l}\text { Awareness of negative environmental consequences of tourism has an effect on personal } \\
\text { norms about environmentalism (H1a) }\end{array}$ \\
\hline $1 \mathrm{~b}$ & $\begin{array}{l}\text { Awareness of the positive consequences of environmental protection has an effect on } \\
\text { personal norms about environmentalism (H1b) }\end{array}$ \\
\hline $1 \mathrm{c}$ & $\begin{array}{l}\text { Awareness of disaster consequences has an effect on personal norms about } \\
\text { environmentalism (H1c) }\end{array}$ \\
\hline $2 \mathrm{a}$ & $\begin{array}{l}\text { Personal norms about environmentalism affect daily environmental conservation } \\
\text { behaviors (H2a) }\end{array}$ \\
\hline $2 \mathrm{~b}$ & $\begin{array}{l}\text { Personal norms about environmentalism affect concern for environmental protection at } \\
\text { tourist sites (H2b) }\end{array}$ \\
\hline $3 \mathrm{a}$ & $\begin{array}{l}\text { Awareness of negative environmental consequences of tourism has an effect on } \\
\text { environment attachment (H3a) }\end{array}$ \\
\hline $3 \mathrm{~b}$ & $\begin{array}{l}\text { Awareness of positive consequences of environmental protection has an effect on } \\
\text { environment attachment (H3b) }\end{array}$ \\
\hline $3 \mathrm{c}$ & Awareness of disaster consequences has an effect on environment attachment (H3c) \\
\hline $4 \mathrm{a}$ & Environment attachment affects daily environmental conservation behaviors (H4a) \\
\hline $4 \mathrm{~b}$ & Environment attachment affects concern for environmental protection at tourist sites (H4b) \\
\hline
\end{tabular}

A number of scholars in the field of human-environment studies assume that strong ties between individuals and their socio-physical environments will lead them to adopt more environmentally friendly lifestyles [30]. Furthermore, place attachment has a powerful role in predicting environmental conservation behaviors, and many empirical researches have validated the positive impact of place attachment on environmental conservation behaviors [6,14,21,47]. Local environment is one aspect of place, so environment attachment is a dimension of place attachment; therefore, the final two hypotheses—4a and $4 \mathrm{~b}$-were proposed (Table 1 ).

\section{Methods}

\subsection{Study Area}

The Great Jiuzhai Tourism Area is located in Sichuan, China, and the core zone comprises Aba Tibetan and Qiang Autonomous prefectures (Figure 1). We selected three tourist sites as our target areas: Jiuzhai Valley, Mount Qingcheng, and the Dujiangyan Irrigation System. Jiuzhai Valley $\left(30^{\circ} 35^{\prime}-34^{\circ} 19^{\prime} \mathrm{N}, 100^{\circ} 30^{\prime}-104^{\circ} 27^{\prime} \mathrm{E}\right)$ is located around Min Shan Mountain in northern Sichuan. Home to more than just spectacular scenery, Jiuzhai Valley is a sacred place in Buddhist culture, a fact that has influenced the Tibetans' environmental ethics and behaviors for generations. Mount Qingcheng $\left(30^{\circ} 54^{\prime} \mathrm{N}, 103^{\circ} 35^{\prime} \mathrm{E}\right)$ is located in the western part of the Chengdu Plain, at the junction between the Sichuan Basin and the Qinghai-Tibet Plateau. Mount Qingcheng is the sacred birthplace of the indigenous Chinese religion of Taoism. The Taoist ecological view of wuweierzhi (govern by doing nothing that goes against nature) and daofaziran (the law of the Tao is its being what it is) deeply influences the cognition of Chinese people regarding the relationship between humans and nature. The Dujiangyan Irrigation System $\left(30^{\circ} 59^{\prime} \mathrm{N}, 103^{\circ} 37^{\prime} \mathrm{E}\right)$ is located in the western part of Chengdu Plain near Mount Qingcheng. It is not only a monument to a 2000-year-old waterworks and engineering feat but is also used for irrigation and tourism today, and has cultural significance as the symbol of Chinese culture, fully displaying the Taoist creed of "Tao follows nature". Flood control is the key cultural feature of Dujiangyan, which predisposes locals not to destroy natural resources, but rather make full use of them for human services and exchange risk for profit. 


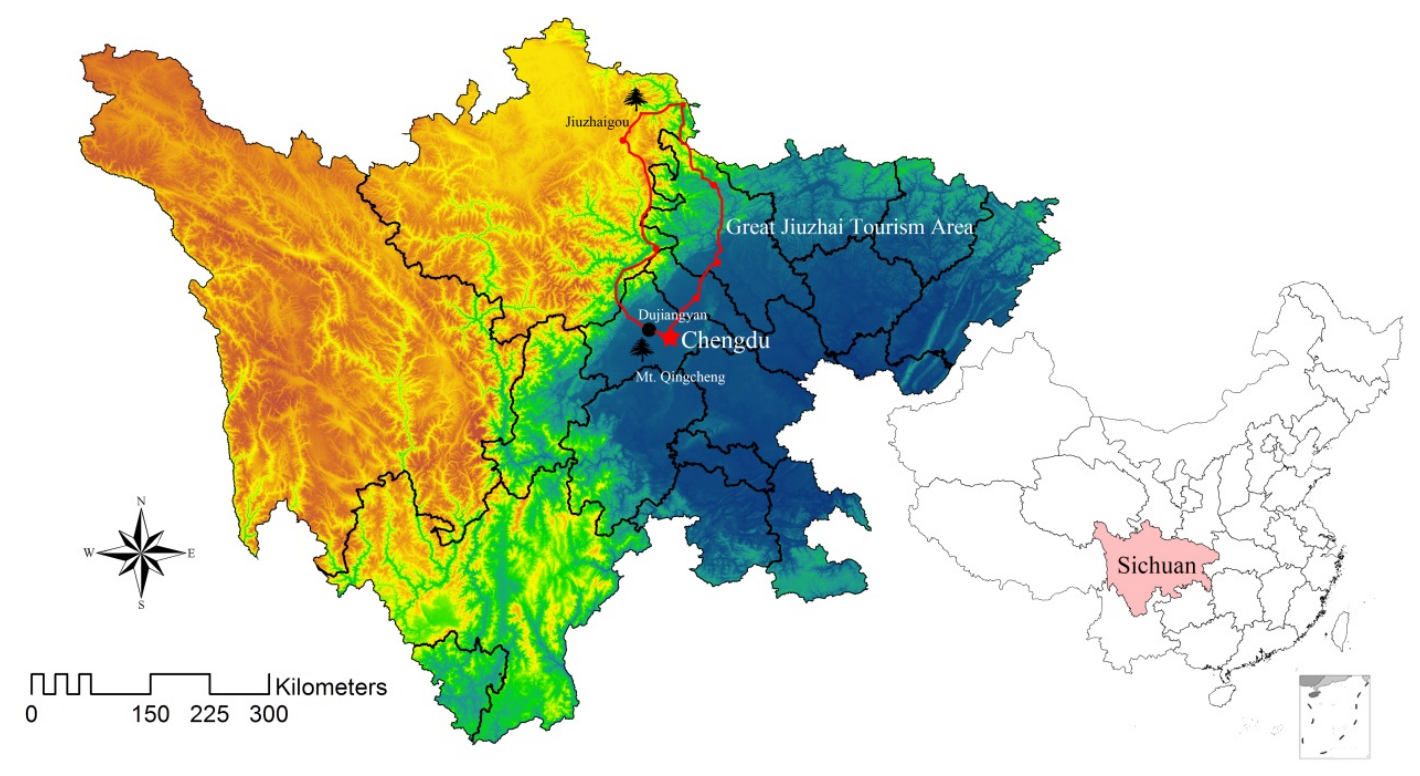

Figure 1. The Great Jiuzhai Tourism Area of China.

\subsection{Data Collection and Analysis}

\subsubsection{Research Instrument}

A questionnaire was developed on the basis of methods used in previous studies, a review of existing literature, and consultation with seven academic experts. Prior to pilot testing, these experts were consulted to assess the clarity, ambiguity, or generality of each item. The pilot survey was conducted with 30 community residents in Jiuzhai Valley on 5 April 2012. The questionnaire items and Likert scales were assessed by examining the Cronbach's alpha, percentage of missing data, mean, standard deviation, item discrimination, skew, kurtosis, correlation coefficients, and factor loadings.

The final questionnaire consisted of five sections. An 11-item scale was developed to measure host residents' awareness of environmental consequences. The items included in this scale were based on previous in-depth interviews and the findings of Ho, Shaw, Lin, and Chiu [48], and Zhang et al. [6]. Four questions aimed at measuring environment attachment were inquiries into residents' environmental dependence, identity, and affection. For environment attachment, the findings presented by Vaske and Kobrin [49] and Lee's works [14] were modified. For the personal norms regarding environmentalism, four items were designed by Zhang et al. [6]. A 6-item scale for environmental conservation behaviors was constructed to assess the extent of residents' intentions to support environmental protection efforts, based on the findings of Choi and Murray [50] and Stern $[11,34]$. Respondents were asked to self-report their demographic status, including gender, age, education level, socioeconomic status, and ethnicity. For each questionnaire item, excluding the questions about demographics, interviewees were asked to indicate the extent of their agreement with the given statements on a 5 -point Likert scale, where $1=$ not at all and $5=$ very much.

\subsubsection{Sampling and Surveying}

The questionnaires were administered using a direct face-to-face survey methodology because of the strength of this method in achieving high response rates. Between 4 and 20 August 2012, the final questionnaire was distributed by five doctoral students and three graduate students majoring in tourism geography. They were hired and trained in research data collection techniques to act as research assistants and to collect survey data. In this study, local community members were selected to be interviewed by the research assistants, who were divided into two groups. One group visited the local residents door-to-door and asked the interviewee if s/he was willing to accept an interview. 
The other group interviewed people who were engaged in tourism-related activities outdoors, and asked whether s/he was a local resident, as well as if s/he was willing to accept an interview.

\subsubsection{Data analysis Technique}

A progressive series of statistical analyses were carried out. First, a basic frequency analysis was conducted to understand the general characteristics of the sample. Second, an exploratory factor analysis was conducted to identify the awareness of environmental consequences, personal norms about environmentalism, and environment attachment, as well as to assess the measurement scales' reliability and validity. Next, a confirmatory factor analysis was conducted using AMOS 17.0 to establish confidence in the measurement model, as it specifies the posited relationships of the observed variables to the underlying constructs. In the final stage, a structural equation model (SEM) with AMOS 17.0 was used to test the hypotheses, as it systematically addresses causal relationships with multiple latent variables, each measured by multiple indicators.

\section{Results}

\subsection{Profile of the Respondents}

A total of 750 surveys (350 at Jiuzhaigou, 200 at Mt. Qingcheng, and 200 at Dujiangyan) were distributed at the three sample sites in the Great Jiuzhai Tourism Area; 688 surveys were returned, and 642 valid surveys were used in the data analysis. The return rate and validity rate of the survey were $91.7 \%$ and $85.6 \%$, respectively. The socio-demographic characteristics of the sample are summarized in Table 2.

Table 2. Socio-demographic profile of samples $(n=642)$.

\begin{tabular}{cccc}
\hline Variables & Percentage & Variables & Percentage \\
\hline Sex & & Age & \\
Females & 64 & 17 and below & 5.4 \\
Males & 46 & $18-24$ & 19.3 \\
Profession & & $25-34$ & 26.9 \\
Government staff & 2.5 & $35-44$ & 24.1 \\
Managers & 6.4 & $45-54$ & 10.6 \\
Professional/technical personnel & 2.3 & 55 or above & 13.7 \\
Businessmen/waiter/salesmen & 41.4 & Education & \\
workers & 3.1 & Primary school and below & 8.1 \\
Farmers & 12.6 & Middle school & 33.1 \\
Soldiers & 0.2 & High school & 36.1 \\
Students & 7.6 & College and above & 22.7 \\
Other & 19.5 & Income (RMB) & \\
Ethnic & 1000 and below & 15.1 \\
Tibetan & 30.7 & $1001-2500$ & 55.7 \\
Qiang & 6.9 & $2501-4000$ & 16.1 \\
Han & 55.3 & $4001-6500$ & 7.9 \\
Other & 7.1 & 6501 and above & 5.2 \\
\hline
\end{tabular}

\subsection{The Measurement Model}

\subsubsection{Fact Extraction and Assessment of the Measurement Scales' Reliability}

All items loading $>0.50$, the Alpha reliability $(>0.60)$ and $\mathrm{KMO}(>0.55)$ value of the measurement scales, were acceptable [51]. In general, items with "corrected item-to-total correlations" below 0.30 were eliminated. Only A8 had item-to-total correlations below 0.30. Therefore, A8 was eliminated from the questionnaire. Three factors (awareness of negative environmental consequences of tourism, awareness of positive consequences of environmental protection, and awareness of disaster consequences) were extracted from the measurement scale of awareness of environmental consequence, 
and two factors (daily environmental conservation behaviors, and concern for environmental protection at tourist sites) were extracted from the measurement scale of environmental conservation behaviors. One factor was extracted from each the measurement scales of personal norms about environmentalism and environment attachment, respectively. In total, seven factors were extracted from four measurement scales (Table 3).

Table 3. Exploratory factor analysis.

\begin{tabular}{|c|c|c|c|c|c|}
\hline Scales & & Factor Loading & & Mean (S.D.) & $\begin{array}{l}\text { Items-Total } \\
\text { Correlation }\end{array}$ \\
\hline \multicolumn{6}{|c|}{ Measurement scale of awareness of environmental consequences } \\
\hline$(\alpha=0.86 \mathrm{KMO}=0.81)$ & $\mathrm{ANC}^{\mathrm{a}}$ & $\mathrm{APC}^{\mathrm{b}}$ & $\mathrm{ADC}^{\mathrm{c}}$ & & \\
\hline $\begin{array}{l}\text { A1: Tourism generates noise, air or } \\
\text { water pollution in local }\end{array}$ & 0.64 & & & 3.44 & 0.37 \\
\hline $\begin{array}{l}\text { A2: Excessive population pressure on } \\
\text { the tourist site in peak season }\end{array}$ & 0.70 & & & 3.60 & 0.42 \\
\hline $\begin{array}{l}\text { A3: Tourism will affect the normal } \\
\text { growth of plants and animals }\end{array}$ & 0.62 & & & 3.23 & 0.45 \\
\hline $\begin{array}{l}\text { A4: Protection of tourist site's } \\
\text { environment benefit everyone }\end{array}$ & & 0.59 & & 4.40 & 0.40 \\
\hline $\begin{array}{l}\text { A5: Protection of tourist site's } \\
\text { environment is good for me } \\
\text { and descendants }\end{array}$ & & 0.71 & & 4.49 & 0.47 \\
\hline $\begin{array}{l}\text { A6: Protection of tourist site's } \\
\text { environment is good for my health }\end{array}$ & & 0.70 & & 4.45 & 0.44 \\
\hline $\begin{array}{l}\text { A7: Our lives will be better if tourist } \\
\text { site's environment was protected well }\end{array}$ & & 0.58 & & 4.46 & 0.38 \\
\hline $\begin{array}{l}\text { A8: I have experienced disaster } \\
\text { here (deleted) }\end{array}$ & & & 0.23 & 4.46 & 0.24 \\
\hline $\begin{array}{l}\text { A9: Natural disasters destroy the } \\
\text { eco-environment of tourist sites }\end{array}$ & & & 0.41 & 3.93 & 0.33 \\
\hline $\begin{array}{l}\text { A10: Natural disasters here affect } \\
\text { our lives }\end{array}$ & & & 0.66 & 4.11 & 0.48 \\
\hline $\begin{array}{l}\text { A11: Natural disasters destroy the } \\
\text { landscape and tourist facilities }\end{array}$ & & & 0.62 & 4.18 & 0.40 \\
\hline \multicolumn{6}{|c|}{ Measurement scale of awareness of environment attachment } \\
\hline$(\alpha=0.90 \mathrm{KMO}=0.83)$ & $\mathrm{EA}^{\mathrm{d}}$ & & & & \\
\hline $\begin{array}{l}\text { E1: I would not substitute } \\
\text { any other place for living, as } \\
\text { environmental considerations }\end{array}$ & 0.73 & & & 4.18 & 0.72 \\
\hline $\begin{array}{l}\text { E2: No other natural environment can } \\
\text { compare to this place }\end{array}$ & 0.82 & & & 4.34 & 0.82 \\
\hline $\begin{array}{l}\text { E3: I am very attached to local } \\
\text { green environment }\end{array}$ & 0.80 & & & 4.47 & 0.79 \\
\hline E4: I feel like this place is a part of me & 0.72 & & & 4.37 & 0.71 \\
\hline
\end{tabular}


Table 3. Cont.

\begin{tabular}{|c|c|c|c|c|}
\hline Scales & & Factor Loading & Mean (S.D.) & $\begin{array}{l}\text { Items-Total } \\
\text { Correlation }\end{array}$ \\
\hline \multicolumn{5}{|c|}{ Measurement scale of awareness of personal norm about environmentalism } \\
\hline$(\alpha=0.84 \mathrm{KMO}=0.80)$ & $P E^{\mathrm{e}}$ & & & \\
\hline $\begin{array}{l}\text { P1: I have the obligation to } \\
\text { dissuade anyone from damaging } \\
\text { the local environment }\end{array}$ & 0.53 & & 4.34 & 0.77 \\
\hline $\begin{array}{l}\text { P2: I have the obligation to comply } \\
\text { with local environmental regulations } \\
\text { and laws }\end{array}$ & 0.75 & & 4.37 & 0.82 \\
\hline $\begin{array}{l}\text { P3: I have the obligation to protect the } \\
\text { local environment }\end{array}$ & 0.80 & & 4.41 & 0.71 \\
\hline $\begin{array}{l}\text { P4: I have the obligation to alleviate } \\
\text { local environmental problems caused } \\
\text { by my daily life }\end{array}$ & 0.63 & & 4.34 & 0.76 \\
\hline \multicolumn{5}{|c|}{ Measurement scale of environmental conservation behaviors } \\
\hline$(\alpha=0.78 \mathrm{KMO}=0.75)$ & $\mathrm{DECB}^{\mathrm{f}}$ & CEP $\mathrm{g}$ & & \\
\hline $\begin{array}{l}\text { B1: Disposing of garbage regularly in } \\
\text { daily life }\end{array}$ & 0.51 & & 4.35 & 0.77 \\
\hline $\begin{array}{l}\text { B2: Protecting animals and plants in } \\
\text { daily life }\end{array}$ & 0.55 & & 4.36 & 0.76 \\
\hline $\begin{array}{l}\text { B3: Saving energy and resource in } \\
\text { daily life }\end{array}$ & 0.53 & & 4.21 & 0.66 \\
\hline $\begin{array}{l}\text { B4: I thought about the government's } \\
\text { environmental policies and } \\
\text { measurements concerning the tourist } \\
\text { site in the past year }\end{array}$ & & 0.53 & 3.81 & 0.62 \\
\hline $\begin{array}{l}\text { B5: I contributed to the } \\
\text { eco-environmental protection or } \\
\text { construction of the tourist site in } \\
\text { the past year }\end{array}$ & & 0.59 & 3.74 & 0.71 \\
\hline $\begin{array}{l}\text { B6: I was concerned about the impact of } \\
\text { tourism on the eco-environment of } \\
\text { tourist site in the past year }\end{array}$ & & 0.45 & 3.81 & 0.68 \\
\hline
\end{tabular}

Kaiser-Meyer-Olkin = 0.86, Cronbach's Alpha $=0.87$

${ }^{a}$ ANC $=$ awareness of negative environmental consequences of tourism; ${ }^{b}$ APC $=$ awareness of positive consequences of environmental protection; ${ }^{\mathrm{c}} \mathrm{ADC}=$ awareness of disaster consequences; ${ }^{\mathrm{d}} \mathrm{EA}=$ environment attachment; ${ }^{\mathrm{e}} \mathrm{PE}=$ personal norm about environmentalism; ${ }^{\mathrm{f}} \mathrm{DECB}=$ daily environmental conservation behaviors; ${ }^{\mathrm{g}} \mathrm{CEP}=$ concern of environmental protection at tourist sites.

\subsubsection{Empirical Validation of the Measurement Model}

Created by maximum likelihood estimation, a confirmatory factor analysis was computed to measure seven constructs (Table 4). All construct loadings were higher than the threshold of 0.45 except A9 [52]. All composite reliability values exceeded 0.60, demonstrating that the latent variables had a high degree of internal consistency [14]. The measurement for the latent variables reached convergent validity at the item level because almost all construct loadings exceeded 0.50 and because all $t$-values associated with each completely standardized loading exceeded 1.96, reaching statistical significance, providing evidence of convergent validity [52]. Discriminant validity was evaluated using AVE; for this assessment, the criterion was that average variance should exceed 0.50 [52]. In this study, except for awareness of negative environmental consequences of tourism (0.49) and awareness of disaster consequences (0.44), the AVE for other constructs exceeded the threshold of 0.50 , indicating that this study had accepted discriminant validity. The model calculated absolute fit measures, yielding a root 
mean squared error of approximation (RMSEA) of 0.05 and a root mean square residual (RMR) of 0.03; a $x^{2} / d f$ of 2.68; a goodness-of-fit index (GFI) of 0.93; and a normed fit index (NFI) of 0.91 , larger than the threshold of 0.90 , meaning that the measurement model is an acceptable fit to the data.

Table 4. Confirmatory factor analysis.

\begin{tabular}{|c|c|c|c|c|c|c|c|}
\hline Construct & Construct Loadings & $\mathrm{CR}^{\mathrm{h}}$ & $\operatorname{AVE}^{i}$ & Construct & Construct Loadings & CR & AVE \\
\hline $\mathrm{ANC}$ & & 0.73 & 0.49 & $\mathrm{PE}$ & & 0.85 & 0.59 \\
\hline A1 & $0.64(* * * j)$ & & & P1 & $0.73(* * *)$ & & \\
\hline A2 & $0.76{ }^{(* * *)}$ & & & P2 & $\left.0.87{ }^{* * *}\right)$ & & \\
\hline $\mathrm{A} 3$ & $0.67{ }^{(* * *)}$ & & & P3 & $0.82\left(^{(* * *)}\right.$ & & \\
\hline APC & & 0.82 & 0.53 & P4 & $0.63(* * *)$ & & \\
\hline A4 & $0.70(* * *)$ & & & DECB & & 0.82 & 0.60 \\
\hline A5 & $0.80(* * *)$ & & & B1 & $0.80(* * *)$ & & \\
\hline A6 & $0.75(* * *)$ & & & B2 & $0.84(* * *)$ & & \\
\hline A7 & $0.66(* * *)$ & & & B3 & $\left.0.67{ }^{* * *}\right)$ & & \\
\hline ADS & & 0.69 & 0.44 & & & 0.75 & 0.50 \\
\hline A9 & $0.39{ }^{(* * *)}$ & & & B4 & $0.64(* * *)$ & & \\
\hline A10 & $0.82(* * *)$ & & & B5 & $\left.0.80{ }^{* * *}\right)$ & & \\
\hline A11 & $\left.0.711^{* * *}\right)$ & & & B6 & $\left.0.677^{* * *}\right)$ & & \\
\hline EA & & 0.90 & 0.69 & & & & \\
\hline E1 & $0.79\left(^{* * *}\right)$ & & & & & & \\
\hline E2 & $0.88(* * *)$ & & & & & & \\
\hline E3 & $\left.0.85{ }^{* * *}\right)$ & & & & & & \\
\hline E4 & $0.79\left(^{* * *}\right)$ & & & & & & \\
\hline \multicolumn{8}{|c|}{$\chi^{2} / d f=2.68, \mathrm{RMR}^{\mathrm{k}}=0.03, \mathrm{GFI}^{1}=0.93, \mathrm{NFI}^{\mathrm{m}}=0.91, \mathrm{IFI}^{\mathrm{n}}=0.94, \mathrm{PNFI}^{\circ}=0.76$, RMSEA $^{\mathrm{P}}=0.05$} \\
\hline
\end{tabular}

\subsection{The Structural Model}

\subsubsection{Testing Overall Model}

Nunnally suggested that in SEM estimation, a good rule is to have at least 10 times as many subjects as variables [53]. There are 24 measurement indicators in the SEM for this study, which means at least 240 samples were required. As such, the 642 samples in this study are large enough for adequate analysis. The overall model performed well, with a good fit for data analysis via the SEM used. This can be seen in Table 5, and because all indices achieved related criteria, the conceptual model can be statistically accepted.

Table 5. Summary of model fit.

\begin{tabular}{|c|c|c|c|c|c|c|c|c|c|c|c|}
\hline \multirow{2}{*}{ Fit Index } & \multicolumn{4}{|c|}{ Absolute Indices } & \multicolumn{7}{|c|}{ Relative Indices Parsimony Indices } \\
\hline & $\chi^{2} / d f$ & GFI & RMR & RMSEA & NFI & IFI & CFI ${ }^{q}$ & PGFI $^{r}$ & PNFI & PCFI $^{s}$ & $\mathrm{CN}^{\mathrm{t}}$ \\
\hline Criterias & $<3.00$ & $>0.90$ & $<0.05$ & $<0.08$ & $>0.90$ & $>0.90$ & $>0.90$ & $>0.50$ & $>0.50$ & $>0.50$ & $>200$ \\
\hline Model & 2.89 & 0.93 & 0.03 & 0.05 & 0.90 & 0.93 & 0.93 & 0.73 & 0.78 & 0.81 & 272 \\
\hline
\end{tabular}

${ }^{\mathrm{q}} \mathrm{CFI}=$ comparative fit index; ${ }^{\mathrm{r}} \mathrm{PGFI}=$ parsimony good-of-fit index; ${ }^{\mathrm{s}} \mathrm{PCFI}=$ parsimony comparative fit index; ${ }^{\mathrm{t}} \mathrm{CN}=$ critical $\mathrm{N}$.

The causal relationships and correlations of each path are shown in Figure 2. The SEM analysis revealed that the awareness of negative environmental consequences of tourism insignificantly affect personal norms about environmentalism $\left(\gamma_{11}=0.04, t=0.904, p>0.05\right)$ and environment attachment $\left(\gamma_{12}=-0.04, t=-0.783, p>0.05\right)$; the awareness of positive consequences of environmental protection directly, positively, and significantly affect personal norms about environmentalism $\left(\gamma_{21}=0.64\right.$, $t=11.043, p<0.001)$ and environment attachment $\left(\gamma_{22}=0.43, t=7.614, p<0.001\right)$; and the awareness of disaster consequences significantly affects personal norms about environmentalism $\left(\gamma_{31}=0.18\right.$, 
$t=3.908, p<0.001)$, while it insignificantly affects environment attachment $\left(\gamma_{32}=0.01, t=0.166\right.$, $p>0.05$ ). Personal norms about environmentalism as well as environment attachment directly, positively, and significantly impact daily environmental conservation behaviors (personal norms' impact: $\beta_{11}=0.37, t=7.801, p<0.001$; environment attachment's impact: $\beta_{21}=0.30, t=6.216, p<0.001$ ) and conservational protection at tourist sites (personal norms' impact: $\beta_{12}=0.33, t=6.409, p<0.001$; environment attachment's impact: $\beta_{22}=0.18, t=3.567, p<0.001$ ). Thus, the results support hypotheses $1 b, 1 c, 2 a, 2 b, 3 b, 4 a$, and $4 b$, while 1a, 3a, and 3c were rejected.

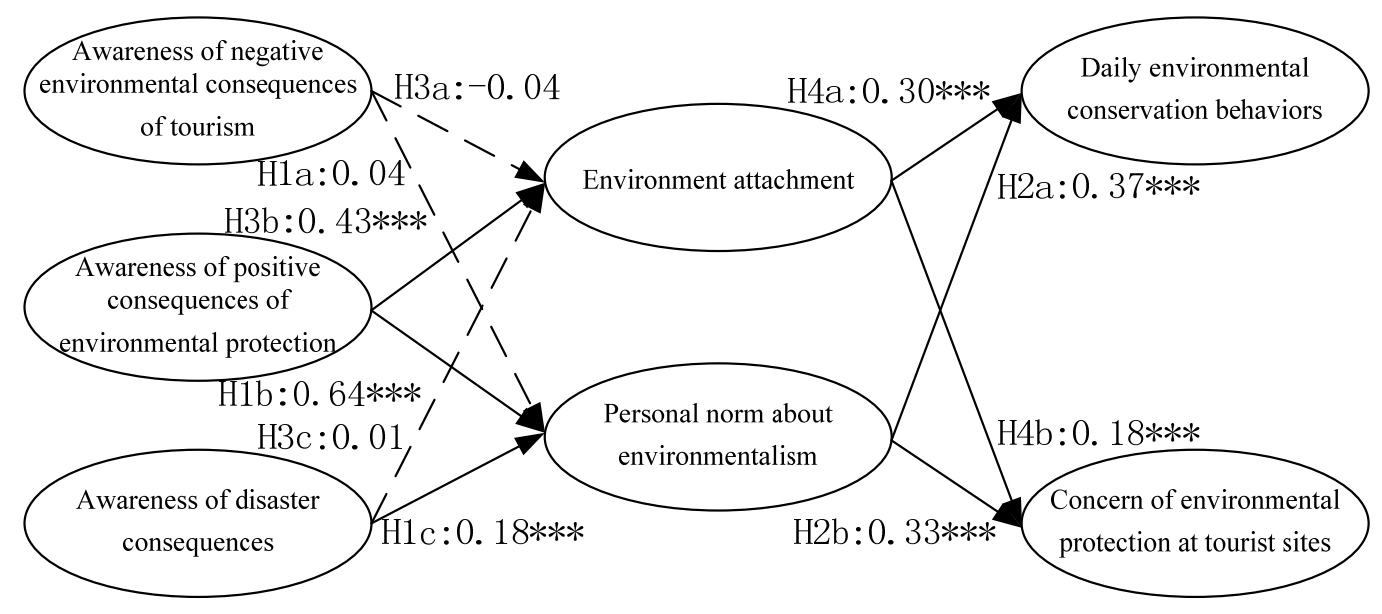

Figure 2. The estimated structural equation model. Insignificant- $--\rightarrow$; Significant $\longrightarrow$; $* * *$ Significant at $p<0.001$.

\subsubsection{Comparing the Impact of Each Factor on Environmental Conservation Behaviors}

As shown in both Table 6 and Figure 2, only personal norms about environmentalism and environment attachment directly influence environmental conservation behaviors at tourist sites (including daily environmental conservation behaviors and concern of environmental protection at tourist sites), and personal norms about environmentalism played a more decisive role than environment attachment in determining residents' environmental conservation behaviors. Awareness of positive consequences of environmental protection was a more important factor among the three dimensions of awareness of environmental consequences to predict environmental conservation behaviors. Compared with awareness of disaster consequences, awareness of positive consequences of environmental protection had a stronger indirect impact on environmental conservation behaviors. Awareness of negative environmental consequences of tourism had neither a direct nor an indirect impact on environmental conservation behaviors. Both the total impact of personal norms about environmentalism on daily environmental conservation behaviors and the total impact of personal norms about environmentalism on concern for environmental protection at tourist sites were stronger than awareness of disaster consequences, awareness of positive consequences of environmental protection, and environment attachment's impact. Therefore, personal norms about environmentalism were the most powerful predictor among all influence factors in this study. In addition, all factors except awareness of negative environmental consequences of tourism had more powerful effects on daily environmental conservation behaviors than on concern for environmental protection at tourist sites. 
Table 6. The impact of each factor on environmental conservation behaviors.

\begin{tabular}{|c|c|c|c|c|c|c|}
\hline \multirow{2}{*}{ Factor } & \multicolumn{3}{|c|}{$\begin{array}{l}\text { Daily Environmental } \\
\text { Conservation Behaviors }\end{array}$} & \multicolumn{3}{|c|}{$\begin{array}{l}\text { Concern of Environmental } \\
\text { Protection at Tourist Sites }\end{array}$} \\
\hline & $\begin{array}{l}\text { Direct } \\
\text { impact }\end{array}$ & $\begin{array}{c}\text { Indirect } \\
\text { impact }\end{array}$ & $\begin{array}{l}\text { Total } \\
\text { impact }\end{array}$ & $\begin{array}{l}\text { Direct } \\
\text { impact }\end{array}$ & $\begin{array}{c}\text { Indirect } \\
\text { impact }\end{array}$ & $\begin{array}{c}\text { Total } \\
\text { impact }\end{array}$ \\
\hline $\begin{array}{l}\text { Awareness of negative } \\
\text { environmental consequences } \\
\text { of tourism }\end{array}$ & $-^{\mathrm{u}}$ & - & - & - & - & - \\
\hline $\begin{array}{l}\text { Awareness of positive } \\
\text { consequences of } \\
\text { environmental protection }\end{array}$ & - & 0.32 & 0.32 & - & 0.19 & 0.19 \\
\hline $\begin{array}{l}\text { Awareness of } \\
\text { disaster consequences }\end{array}$ & - & 0.07 & 0.07 & - & 0.06 & 0.06 \\
\hline Environment attachment & 0.30 & - & 0.30 & 0.18 & - & 0.18 \\
\hline $\begin{array}{l}\text { Personal norm about } \\
\text { environmentalism }\end{array}$ & 0.37 & - & 0.37 & 0.33 & - & 0.33 \\
\hline
\end{tabular}

$-^{\mathrm{u}}=$ no significant influence.

\section{Discussion}

\subsection{The Role of Awareness of Environmental Consequences in Predicting Environmental Conservation Behaviors}

Awareness of the positive consequences of environmental protection had an indirect impact on environmental conservation behaviors via personal norms about environmentalism or environment attachment. Awareness of disaster consequences affected environmental conservation behaviors only if it was mediated by personal norms about environmentalism. Therefore, the simplified norm-activation model was partly verified by path analyses, providing empirical support for the hypothesis that awareness of environmental consequences directly activates personal norms, thereby compelling people to perform environmentalist behaviors [36,37] — a process different from the classic causal chain that emphasizes the mediating role of AR between AC and personal norms [8,31,54]. Meanwhile, the cognitive-affective model was also partly verified, consistent with the results of Zhang et al. [15], Han et al. [45], and Huynh [55]. On the basis of the results obtained, residents with greater awareness of the positive consequences of environmental protection and of disaster consequences were more likely to participate in environmental conservation at tourist sites. This result indicates that residents will develop active concern for the quality of the local environment and will either implement or participate in environmental conservation behaviors as long as they recognize that the protection of the local environment will benefit their lives, particularly if the benefit is economical [56], or that disasters will negatively affect their lives and interests. It is crucial for local governments to introduce and publicize their efforts to benefit local residents (e.g., providing employment opportunities and tourism skills training, improving the quality of the living environment, and distributing reasonable tourism dividend payments to residents) as well as scenic environment management policies and communicating the potential impacts of environmental disasters (e.g., destruction of local environmental quality, reduction of resource attraction, disruption of the normal lives of residents, impact on tourism revenue) [21].

Awareness of negative environmental consequences of tourism can't affect environmental conservation behaviors via personal norms about environmentalism or environment attachment. It indicates that residents who are aware of the negative environmental consequences of tourism that do not have significant direct negative impacts on their well-being will not implement or participate in environmental conservation behaviors at tourist sites. Therefore, governments need to publicize the harmful environmental impacts caused by tourism (e.g., habitat destruction; disturbance of animals and plants; air, water, and waste pollution; and litter), and educate residents on the relationship 
between the environment and the interests of local residents via media, public notices, and community meetings. Further, formulating relevant environmental laws and regulations-especially related to punishment measures-and taking action to implement these in tourism communities are also important ways to deal with environmental vandalism [57].

\subsection{The Role of Personal Norms about Environmentalism in Predicting Environmental Conservation Behaviors}

Personal norms about environmentalism played an important role in linking awareness of positive consequences of environmental protection, awareness of disaster consequences [58,59], and environmental conservation behaviors. Furthermore, personal norms about environmentalism were strongly related to environmental conservation behaviors, and this was the strongest factor for predicting environmental conservation behaviors among all influencing factors in this study. The importance of personal norms for predicting environmentalist behaviors supports the results of Nordlund and Garvill [60], and Zhang et al. [6] results. A group's norms and behaviors are impacted by their ethnic culture, and cultural norms strongly influence behaviors [61]. Therefore, cultivating residents' personal norms and responsibility to protecting the environment and promoting traditional Chinese virtues (e.g., maintaining a harmonious relationship between humans and nature) would be particularly effective in this study area. To achieve the above target, it is important for government, communities, and residents to act together. It is the government's responsibility to formulate and implement relevant education policies aligned with traditional Chinese culture and to take action to implement them not only in schools but also within communities. Communities can stimulate residents to study traditional culture by, for example, holding calligraphy exhibitions for community residents and introducing other traditional culture classes to communities. These would emphasize and promote the meaning of traditional culture and harmony in daily life, as well as stimulate their passion for practical environmental conservation action. Residents should establish responsibility for the social and ecological environment via emphasizing traditional culture, moral norms and responsibility, and traditional family education.

\subsection{The Role of Environment Attachment in Predicting Environmental Conservation Behaviors}

The relationship between environment attachment and environmental conservation behaviors was established through the methods and results of this study. It supports Yang's result that environment attachment is significantly correlated to the local level pro-environmental behaviors [62]. An individual will experience increased dependence on a setting, ultimately leading to an emotional attachment with an area, if the place satisfies his or her needs and goals [49,63]. Local environment as an aspect of place not only provides the natural elements of survival on which residents rely, but also provides leisure and travel resources for visitors. Currently, both the government and individuals in China prioritize the economy, while tourism, as an economic instrument, not only provides an opportunity to develop the local economy but also direct and indirect employment opportunities for residents. As such, residents' household income and quality of life, to a large extent, depend on tourism. Meanwhile, the natural environment serves as the base of tourism, so residents who live in tourism-dependent communities are very attached to the area and are eager to protect it, because its eco-environmental features are closely associated with their personal interests and survival [64]. At the level of policy making, the role of environment attachment should be taken into account. Resident-based environmental policies, such as expanding public participation, increasing financial expenditure for local environmental governance, and implementing plans for community-beautification selection and ecological civilization city construction are more likely to enhance residents' environment attachment, receive higher consensus and public support, and thus be more effective in the long run.

\section{Conclusions}

This study extends the existing body of knowledge on environmental conservation behaviors by innovatively investigating the common effects of awareness of environmental consequences, 
personal norms about environmentalism, and environment attachment on environmental conservation behaviors. Empirical tests of the proposed model provided the following evidence: (1) two dimensions of residents' awareness of environmental consequences-awareness of the positive consequences of environmental protection and awareness of disaster consequences-influenced their environmental conservation behaviors but these were mediated by personal norms about environmentalism at tourist sites; (2) residents' environment attachment directly affected their environmental conservation behaviors and played a mediating role between awareness of the positive consequences of environmental protection and environmental conservation behaviors at tourist sites; and (3) personal norms about environmentalism were a more powerful predictor of environmental conservation behaviors than awareness of environmental consequences or environment attachment.

\subsection{Implications}

From a theoretical standpoint, this study builds a comprehensive and relative effective model to predict environmentally relevant behaviors by combining the norm-activation model and the cognitive-affective model. It can be broadly utilized for theory and model development in a variety of environmental contexts. From a practical standpoint, effectively promoting locals' awareness of positive consequences of environmental protection, awareness of disaster consequences, personal norms about environmentalism, and environment attachment by implementing valid environmental management measures (e.g., expanding community participation in environmental management, public environmental policies and information, and combining government, community, and residents for environmental and traditional culture education) can be a helpful approach in promoting residents' environmental conservation behaviors. It's crucial for environmental management and environment sustainability especially in natural-based communities. Because resident-based environmental measures are more likely to get higher consensus and public support, and are more efficacious in the long run. Facing invalid predictors of residents' awareness regarding the negative environmental consequences of tourism, it is necessary to formulate and implement relevant environmental administrative penalties and improve residents' environmental knowledge.

\subsection{Limitations and Future Studies}

Although the comprehensive constructs of this study significantly predicted residents' environmental conservation behaviors, it was verified only in tourist sites within a singular country. Residents' lives, livelihoods, well-being, and economic interests highly depend on local resources and the environment at tourist sites. Conclusions about whether the results of and suggestions provided by this study will serve a universal need require more cases for validation, particularly in countries with different cultural and economic conditions. Further, residents in other communities who are not highly depend on local resources and the environment might hold differing opinions regarding environmental conservation. To overcome this limitation, future studies should conduct similar surveys across a wide spectrum of community types such as urban communities, those that lack natural resources, and low environmental quality communities. In addition, further research is necessary to investigate data pertaining to host residents over the course of multiple years to better understand this model; for example, it would be useful to perform a longitudinal study of the support of residents for environmental conservation and management.

Acknowledgments: This research was financially supported by National Natural Science Foundation of China (No. 41171121 and No. 41501147), Scientific Platform and Innovation Capability Construction Program of GDAS (2016GDASPT-0210), and High-level Leading Talent Introduction Program of GDAS (2016GDASRC-0101).

Author Contributions: Yuling Zhang and Yuyao Ye contributed to designing, collecting, and analyzing the questionnaires; Jie Zhang and Hongou Zhang made substantial contributions to the paper design, questionnaire design, and critical revisions to the work of Yuling Zhang. Qitao Wu and LixiaJin contributed in data analysis and paper revisions.

Conflicts of Interest: The authors declare no conflicts of interest. 


\section{References}

1. Demiroglu, O.C.; Turp, M.T.; Ozturk, T.; An, N.; Kurnaz, M.L. A refined methodology for modelling climate change impacts on snow sports tourism. In Proceedings of the European Geosciences Union General Assembly Meeting, Vienna, Austria, 12-17 April 2015.

2. Bonzanigo, L.; Giupponi, C.; Balbi, S. Sustainable tourism planning and climate change adaptation in the alps: A case study of winter tourism in mountain communities in the dolomites. J. Sustain. Tour. 2016. [CrossRef]

3. Peric', J.; Grdic', Z.Š. Economic impacts of sea level rise caused by climate change. In Proceedings of the ToSEE-Tourism in Southern \& Eastern Europe, Opatija, Republic of Croatia, 13-16 May 2015.

4. Mishev, P.; Mochurova, M. Climate change impacts on tourism. In Proceedings of the International Conference "Global Environmental Change: Challenges to Science and Society in Southeastern Europe", Sofia, Bulgaria, 19-21 May 2008.

5. Ma, L.; Sun, G.; Ma, Y.; Wang, J.; Su, J. A Study on the influence of extreme weather and climate on tourism: A case on snowstorm in 2008. Res. Sci. 2010, 32, 107-112. (In Chinese)

6. Zhang, Y.; Zhang, H.L.; Zhang, J.; Cheng, S. Predicting residents' pro-environmental behaviors at tourist sites: The role of awareness of disaster's consequences, values, and place attachment. J. Environ. Psychol. 2014, 40, 131-146. [CrossRef]

7. United Nations Environment Programme. Available online: http://www.unep.org/ resourceefficiency/Business/SectoralActivities/Tourism/TheTourismandEnvironmentProgramme/

FactsandFiguresaboutTourism/ImpactsofTourism/EnvironmentalImpacts /

TourismsThreeMainImpactAreas/tabid/78776/Default.aspx (accessed on 19 May 2016).

8. Schwartz, S.H. Normative influences on altruism 1. Adv. Exp. Soc. Psychol. 1977, 10, 221-279.

9. Ajzen, I. The theory of planned behavior. Organ. Behav. Hum. Decis. Process. 1991, 50, 179-211. [CrossRef]

10. Ajzen, I.; Fishbein, M. Understanding Attitudes and Predicting Social Behaviour; Prentice Hall: London, UK, 1980.

11. Stern, P.C. New environmental theories: Toward a coherent theory of environmentally significant behavior. J. Soc. Iss. 1999, 56, 407-424. [CrossRef]

12. Ramkissoon, H. Place attachment and pro-environmental behavior in national parks: The development of a conceptual framework. J. Sustain. Tour. 2012, 20, 257-276. [CrossRef]

13. Halpenny, E.A. Pro-environmental behaviours and park visitors: The effect of place attachment. J. Environ. Psychol. 2010, 30, 409-421. [CrossRef]

14. Lee, T.H. How recreation involvement, place attachment, and conservation commitment affect environmentally responsible behavior. J. Sustain. Tour. 2011, 19, 895-915. [CrossRef]

15. Zhang, Y.L.; Zhang, J.; Zhang, H.L.; Cheng, S.W.; Guo, Y.R.; Ma, J.H.; Sun, J.R. The impact of the cognition of landscape experience on tourist environmental conservation behaviors. J. Mt. Sci. 2015, 12, 501-517. [CrossRef]

16. Chiu, Y.H.; Lee, W.-I.; Chen, T-H. Environmentally responsible behavior in ecotourism: Antecedents and implications. Tour. Manag. 2014, 40, 321-329. [CrossRef]

17. Lee, T.H.; Jan, F.H. The effects of recreation experience, environmental attitude, and biospheric value on the environmentally responsible behavior of nature-based tourists. Environ. Manag. 2015, 56, $193-208$. [CrossRef] [PubMed]

18. Lee, T.H.; Jan, F.H.; Huang, G.W. The influence of recreation experiences on environmentally responsible behavior: The case of Liuqiu Island, Taiwan. J. Sustain. Tour. 2015, 23, 947-967. [CrossRef]

19. Lee, T.H.; Jan, F.H. The influence of recreation experience and environmental attitude on the environmentally responsible behavior of community-based tourists in Taiwan. J. Sustain. Tour. 2015, 23, 1063-1094. [CrossRef]

20. Lee, T.H.; Jan, F.-H.; Yang, C.C. Conceptualizing and measuring environmentally responsible behaviors from the perspective of community-based tourists. Tour. Manag. 2013, 36, 454-468. [CrossRef]

21. Lee, T.H. Influence analysis of community resident support for sustainable tourism development. Tour. Manag. 2013, 34, 37-46. [CrossRef]

22. Bernath, K.; Roschewitz, A. Recreational benefits of urban forests: Explaining visitors' willingness to pay in the context of the theory of planned behavior. J. Environ. Manag. 2008, 89, 155-166. [CrossRef] [PubMed]

23. López-Mosquera, N.; Sánchez, M. Theory of planned behavior and the value-belief-norm theory explaining willingness to pay for a suburban park. J. Environ. Manag. 2012, 113, 251-262. [CrossRef] [PubMed] 
24. Zhang, D.; Huang, G.; Yin, X.; Gong, Q. Residents' waste separation behaviors at the source: Using sem with the theory of planned behavior in Guangzhou, China. Int. J. Environ. Res. Public Health. 2015, 12, 9475-9491. [CrossRef] [PubMed]

25. Schwartz, S. The justice of need and the activation of humanitarian norms. J. Soc. Iss. 1975, 31, 111-136. [CrossRef]

26. Nordfjærn, T.; Rundmo, T. Environmental norms, transport priorities and resistance to change associated with acceptance of push measures in transport. Transp. Policy. 2015, 44, 1-8. [CrossRef]

27. Han, H.; Han, H. Travelers' pro-environmental behavior in a green lodging context: Converging value-belief-norm theory and the theory of planned behavior. Tour. Manag. 2015, 47, 164-177. [CrossRef]

28. Chen, M.F.; Tung, P.J. Developing an extended theory of planned behavior model to predict consumers' intention to visit green hotels. Int. J. Hosp. Manag. 2014, 36, 221-230. [CrossRef]

29. Relph, E.C. Place and Placelessness; Pion Limited: London, UK, 1976.

30. Carrus, G.; Scopelliti, M.; Fornara, F.; Bonnes, M.; Bonaiuto, M. Place attachment, community identification, and pro-environmental engagement. In Place Attachment: Advances in Theory, Methods and Applications; Lynne, M., Patrick, D.-W., Eds.; Routledge: London, UK; New York, NY, USA, 2013; pp. 176-192.

31. Schwartz, S.H. Moral decision making and behavior. In Altruism and Helping Behavior; Macauley, J., Berko-lvitz, L., Eds.; Acvances: New York, NY, USA, 1970; pp. 127-141.

32. Matthies, E.; Selge, S.; Klöckner, C.A. The role of parental behaviour for the development of behaviour specific environmental norms - the example of recycling and re-use behaviour. J. Environ. Psychol. 2012, 32, 277-284. [CrossRef]

33. Linden, S.V.D. Exploring beliefs about bottled water and intentions to reduce consumption: The dual-effect of social norm activation and persuasive information. Environ. Behav. 2013, 47, 526-550. [CrossRef]

34. Stern, P.C.; Kalof, L.; Dietz, T.; Guagnano, G.A. Values, beliefs, and proenvironmental action: Attitude formation toward emergent attitude objects 1. J. Appl. Soc. Psychol. 1995, 25, 1611-1636. [CrossRef]

35. Zhang, Y.L.; Zhang, J.; Zhang, H.L.; Cheng, S.W.; Ma, J.H.; Sun, J.R. Impact of culture and natural disasters on residents' behaviors toward eco-environmental conservation: Sichuan province case studies. Acta Ecol. Sin. 2014, 34, 5103-5113. (In Chinese) [CrossRef]

36. Zhang, Y.L.; Zhang, J.; Cheng, S.W.; Zhao, W. Analysis of the impacts of residents' cognition of environmental consequences on behaviors toward environmental conservation in tourist destination. China Popul. Res. Environ. 2014, 24, 149-156. (In Chinese)

37. Harland, P.; Staats, H.; Wilke, H.A.M. Situational and personality factors as direct or personal norm mediated predictors of pro-environmental behavior: Questions derived from norm-activation theory. Basic Appl. Soc. Psych. 2007, 29, 323-334. [CrossRef]

38. Decrop, A. Tourists' Decision-Making and Behavior Processes; The Haworth Hospitality Press: New York, NY, USA, 2000; pp. 103-134.

39. Russell, J.A. A circumplex model of affect. J. Pers. Soc. Psychol. 1980, 39, 1161-1178. [CrossRef]

40. Lazarus, R. Emotion and Adaptation; Oxford University Press: Oxford, UK, 1991.

41. Mischel, W.; Shoda, Y. A cognitive-affective system theory of personality: Reconceptualizing situations, dispositions, dynamics, and invariance in personality structure. Psycholog. R. 1995, 102, 246-268. [CrossRef]

42. Caro, L.M.; García, J.A.M. Cognitive-affective model of consumer satisfaction: An exploratory study within the framework of a sporting event. J. Bus. Res. 2007, 60, 108-114. [CrossRef]

43. Bosque, I.R.D.; Martín, H.S. Tourist satisfaction-A cognitive-affective model. Ann. Tour. Res. 2008, 35, 551-573. [CrossRef]

44. Rojas, C.D.; Camarero, C. Visitors' experience, mood and satisfaction in a heritage context: Evidence from an interpretation center. Tour. Manag. 2008, 29, 525-537. [CrossRef]

45. Han, H.; Kim, Y.; Kim, E.K. Cognitive, affective, conative, and action loyalty: Testing the impact of inertia. Int. J. Hosp. Manag. 2011, 30, 1008-1019. [CrossRef]

46. Oliver, R.L. Cognitive, affective, and attribute bases of the satisfaction response. J. Cons. Res. 1993, 20, 418-430. [CrossRef]

47. Chen, T.-M.; Wu, H.C. How do environmental knowledge, environmental sensitivity, and place attachment affect environmentally responsible behavior? An integrated approach for sustainable island tourism. J. Sustain. Tour. 2015, 23, 557-576. [CrossRef] 
48. Ho, M.C.; Shaw, D.; Lin, S.; Chiu, Y.C. How do disaster characteristics influence risk perception? Risk Anal. 2008, 28, 635-643. [CrossRef] [PubMed]

49. Vaske, J.J.; Kobrin, K.C. Place attachment and environmentally responsible behavior. J. Environ. Educ. 2001, 32, 16-21. [CrossRef]

50. Choi, H.C.; Murray, I. Resident attitudes toward sustainable community tourism. J. Sustain. Tour. 2010, 18, 575-594. [CrossRef]

51. Wu, M. Statistical Analysis of Queationnaire: SPSS Operation and Application; Chongqing University Press: Chongqing, China, 2010. (In Chinese)

52. Wu, M. Structural Equation Model: Operation and Application of the Amos; Chongqing University Press: Chongqing, China, 2009. (In Chinese)

53. Nunnally, J.C. Psychometric Theory, 2nd ed.; McGraw-Hill: New York, NY, USA, 1978.

54. Han, H. The norm activation model and theory-broadening: Individuals' decision-making on environmentally-responsible convention attendance. J. Environ. Psychol. 2014, 40, 462-471. [CrossRef]

55. Huynh, K. Factors Affecting the Success of Viral Marketing An Affective-Cognitive-Behavioral Process. Bus. Manag. Res. 2016, 5, 40-45. [CrossRef]

56. Spencer, D.M.; Nsiah, C. The economic consequences of community support for tourism: A case study of a heritage fish hatchery. Tour. Manag. 2013, 34, 221-230. [CrossRef]

57. Arias, A. Understanding and managing compliance in the nature conservation context. J. Environ. Manag. 2015, 153, 134-143. [CrossRef] [PubMed]

58. Doran, R.; Larsen, S. The relative importance of social and personal norms in explaining intentions to choose eco-friendly travel options. Int. J. Tour. Res. 2016, 18, 159-166. [CrossRef]

59. Lind, H.B.; Rundmo, T.; Nordfjærn, T.; Rundmo, T. The value-belief-norm theory, personal norms and sustainable travel mode choice in urban areas. J. Environ. Psychol. 2015, 44, 119-125. [CrossRef]

60. Nordlund, A.M.; Garvill, J. Effects of values, problem awareness, and personal norm on willingness to reduce personal car use. J. Environ. Psychol. 2003, 23, 339-347. [CrossRef]

61. Mcbreen, J.; Tosto, G.D.; Dignum, F.; Hofstede, G.J. Linking Norms and Culture. In Proceedings of the Second International Conference on Culture and Computing, Kyoto, Japan, 20-22 October 2011.

62. Yang, X. Local Environment Attachment and the Possibility of Using Citizen Science Approaches to Measure Firefly Populations in Time and Place. Ph.D. Thesis, the Ohio State University, Columbus, OH, USA, 2012.

63. Cristoforetti, A.; Gennai, F.; Rodeschini, G. Home sweet home: The emotional construction of places. J. Aging Stud. 2011, 25, 225-232. [CrossRef]

64. Yaman, A.R.; Mohd, A. Community-based ecotourism: A new proposition for sustainable development and environmental conservation in Malaysia. J. Appl. Sci. 2004, 4, 583-589. 